\title{
Helminth infections in Apodemus sylvaticus in southern England: interactive effects of host age, sex and year on the prevalence and abundance of infections
}

\author{
J.M. Behnke ${ }^{1 *}$, J.W. Lewis ${ }^{2}$, S.N. Mohd Zain ${ }^{2}$ and F.S. Gilbert ${ }^{2}$ \\ ${ }^{1}$ School of Biological Sciences, University Park, University of \\ Nottingham, Nottingham, NG7 2RD, UK: ${ }^{2}$ School of Biological \\ Sciences, Royal Holloway University of London, Egham, Surrey, \\ TW20 0EX, UK
}

\begin{abstract}
Helminth parasites were studied in the wood mouse, Apodemus sylvaticus, in southern England in September of each of four successive years (1994-1997). Nine species of helminths were recorded: five nematodes (Heligmosomoides polygyrus, Syphacia stroma, Pelodera strongyloides, Trichuris muris, Capillaria murissylvatici), two cestodes (Microsomacanthus crenata, Taenia taeniaeformis) and two trematodes (Corrigia vitta, Brachylaemus recurvum). In total, 134 mice were examined and $91.8 \%$ carried at least one species of helminth. The majority of mice carried two to three species $(60.5 \%)$ and the highest combination was six of the nine species recorded in the study. The patterns of between-year variations in the prevalence and abundance of infection were different for each of the six species for which sufficient quantitative data were available to enable statistical analysis. For $H$. polygyrus, the most important source of variation arose from between-year differences, host age and the interaction of these factors: abundance increased with host age but in 1995 the age pattern was markedly different from that in the remaining years. The abundance of $C$. vitta also varied significantly between years but additionally there was a strong independent age effect. For $M$. crenata, the year $\times$ age interaction was significant, indicating that abundance among different age cohorts varied from year to year but there was also a weak significant main effect of age arising from the youngest age cohort carrying no parasites and the oldest age cohort the heaviest infections. For P. strongyloides the only significant factor was between-year variation with 1995 being a year of exceptionally low prevalence and abundance of infection. No significant between-year variation was detected for $S$. stroma but there was a strong sex effect (males carrying heavier infections) and an age effect (older mice of both sexes carrying heavier infections). The abundance of Trichuris muris varied only in relation to host age, worm burdens growing in intensity with increasing age, but there was also a significant interaction between year and host sex with respect to prevalence. For the remaining three species, the prevalence of infections was too low $(<8.2 \%)$ to enable any meaningful interpretation. This
\end{abstract}

*Fax: 01159513252

E-mail: jerzy.behnke@nottingham.ac.uk 
analysis emphasizes the need for carefully controlled statistical procedures in aiding the interpretation and the prioritization of the factors affecting worm burdens in wild rodents.

\section{Introduction}

The helminth parasites of wild rodents have been documented over many years from various European study sites. Among the more comprehensive studies on the continent in which ecological factors affecting parasite burdens were taken into account, are those of Polish (Kisielewska, 1970; Kisielewska et al., 1973), Czech (Tenora, 1967; Tenora \& Stanek, 1995) and Finnish authors (Haukisalmi, 1986; Haukisalmi \& Henttonen, 1993) and in the UK and Eire studies by Elton et al. (1931), Lewis (1968), Montgomery \& Montgomery (1988, 1989, 1990) and Langley \& Fairley (1982). Collectively, all these studies have contributed to our understanding of the factors (host species, density, age, sex, site of study, season, year, presence/absence of other parasites, etc.) which explain temporal, locational and host-related variation in helminth richness/diversity and community structure in European rodents. Nevertheless, the relative contribution of the component factors in specific ecosystems has been rarely analysed in context by rigorous statistical analysis.

Seasonal influences on the abundance of helminth infections harboured by rodents are well established (Lewis, 1968; Langley \& Fairley, 1982), and have been shown recently to represent the major determinant of worm burdens with Heligmosomoides polygyrus in field mice, Apodemus sylvaticus in the UK (Abu-Madi et al., 1998). By contrast, relatively little is known about stability/changes over a longer period, stretching across several years (Keymer \& Dobson, 1987). Among published studies sustained over more than a single combination of seasons is that of Haukisalmi et al. (1988) who, during a 10year long project, were able to relate some of the characteristics of the cycles of prevalence with Catenotaenia spp. and Heligmosomum mixtum in Clethrionomys glareolus to cycles of host abundance. Kisielewska (1970) reported on the prevalence of helminths in Białowieża National Park over a period of 9 years and Tenora \& Stanek (1995) compared the helminth infracommunity structure among five species of rodents in Moravia, before and after an interval of some 20 years, attributing the differences to changes in agricultural practices in the region. In the UK and Eire, long-term data sets on rodent helminths are restricted to the 4-year study of Elton et al. (1931) and the extensive 3-year studies of Montgomery \& Montgomery $(1988,1989,1990)$ in Northern Ireland. Remaining studies are based on just a single season (Lewis, 1968; Langley \& Fairley, 1982; O'Sullivan et al., 1984) and provide little data on the longer term stability/fluctuations in the prevalence and abundance of infection and changes in helminth infraand component community structures from one year to the next.

In this paper we present data on the helminth parasites of the long-tailed field mouse (wood mouse), Apodemus sylvaticus, gathered over a 4-year period in September of each year from the same study site previously described by Abu-Madi et al. (1998). Our aim was to rigorously assess the importance of annual changes in parasite fauna, in relation to two intrinsic factors (host sex and age), in explaining variation in the worm burdens of the most abundant helminths in the wood mouse population in the study site.

\section{Materials and methods \\ Collection of mice and parasites}

Mice were collected from a woodland area in the grounds of Royal Holloway, University of London Egham Surrey (Grid reference, 993693). Trapping was carried out for 10 days in September of each year, 1994-1997, using Longworth traps provided with hay and food. Fifty Longworth traps were used each night (representing 500 trap nights per year) and their positions recorded on a local map. Data on rainfall were recorded from a nearby site at Silwood Park, Ascot, Berks (Grid reference 946686) throughout the trapping period.

Mice were retrieved from traps and killed by exposure to a piece of chloroform-soaked cotton wool. For each mouse examined, the date of trapping, locality, body length (head and the body) and sex were noted. For analysis, mice were separated into juveniles and adults, as previously described by Lewis (1968) and Corbet \& Harris (1991). Three age cohorts were established based on approximate body weight with ranges of 1-12 $\mathrm{g}$ (juveniles), 13-19 g (young adults) and $\geq 20 \mathrm{~g}$ (adults).

The alimentary canal was then removed for further examination and the eviscerated body weight of each animal was recorded. The small intestine from pyloric sphincter to caecum was separated from the surrounding fat tissue and placed in a Petri dish containing physiological saline. The small intestine was opened longitudinally and examined for helminth parasites under a low power binocular microscope. The parasites were carefully removed, identified, sexed and counted.

\section{Statistical analysis}

The results are presented as prevalence (percentage of mice infected in each subset) and mean abundance of infection (= mean worm burden of each subset, including uninfected animals, as defined by Margolis et al. (1982) \pm standard error of the mean). The total data comprises three factors (year, sex and age) and two variables (prevalence and number of worms). In all cases significance was set at $P \leq 0.05$.

Prevalence was analysed by maximum likelihood techniques based on log linear analysis of contingency tables implemented by the software package, Statgraphics Version 7. Beginning with the most complex model, involving all possible main effects and interactions, those combinations which did not contribute 
significantly to explaining variation in the data were eliminated stepwise beginning with the least significant. A minimum sufficient model was then obtained, for which the likelihood ratio of $\chi^{2}$ was not significant, indicating that the model was sufficient in explaining the data.

Worm burdens were analysed by GLIM (General Linear Models) using a model with negative binomial errors (only for $H$. polygyrus) as reported previously (Crawley, 1993; Behnke et al., 1994; Wilson \& Grenfell, 1997). We began with the full factorial model involving all possible main effects and interactions and deleted combinations stepwise, commencing with the most complex (the 3-way interaction) until only the main effects remained. At each step (subtraction of the relevant term) the change in model deviance was noted and used to calculate $\chi^{2}$ (change in deviance/scale parameter) and thereby the significance of its contribution to the overall model. The main effects were analysed in turn but each was replaced in the model before evaluation of the remainder. The model was then re-run, including only those combinations which had shown significance (minimum sufficient model), to locate the level at which significant variation resided within factors.

The data for five species did not fit the negative binomial distribution sufficiently closely to enable analysis and/or data were based on largely zero counts in particular subsets (as a consequence of a large number of

Table 1. Mean rainfall ( $\mathrm{mm}$ ) recorded in July, August and the first 14 days in September, 1994-1997.

\begin{tabular}{lllll}
\hline & \multicolumn{4}{c}{ Year } \\
\cline { 2 - 5 } Month & 1994 & 1995 & 1996 & 1997 \\
\hline July & 0.74 & 0.68 & 1.20 & 1.22 \\
August & 0.95 & 0.05 & 2.32 & 3.11 \\
September & 3.26 & 3.51 & 0.24 & 0.43 \\
\hline
\end{tabular}

Table 2. Numbers of Apodemus sylvaticus examined by sex, age and year.

\begin{tabular}{|c|c|c|c|c|c|c|}
\hline \multirow[b]{2}{*}{ Year } & \multirow[b]{2}{*}{ Sex } & \multicolumn{3}{|c|}{ Age } & \multirow{2}{*}{$\begin{array}{c}\text { Total } \\
\text { by sex }\end{array}$} & \multirow{2}{*}{$\begin{array}{c}\text { Total } \\
\text { by year }\end{array}$} \\
\hline & & 1 & 2 & 3 & & \\
\hline \multirow[t]{3}{*}{1994} & Male & 2 & 11 & 14 & 27 & \\
\hline & Female & 2 & 7 & 8 & 17 & \\
\hline & Combined & 4 & 18 & 22 & & 44 \\
\hline \multirow[t]{3}{*}{1995} & Male & 3 & 12 & 6 & 21 & \\
\hline & Female & 1 & 7 & 2 & 10 & \\
\hline & Combined & 4 & 19 & 8 & & 31 \\
\hline \multirow[t]{3}{*}{1996} & Male & 2 & 8 & 13 & 23 & \\
\hline & Female & 2 & 3 & 6 & 11 & \\
\hline & Combined & 4 & 11 & 19 & & 34 \\
\hline \multirow[t]{3}{*}{1997} & Male & 7 & 8 & 5 & 20 & \\
\hline & Female & 2 & 1 & 2 & 5 & \\
\hline & Combined & 9 & 9 & 7 & & 25 \\
\hline \multicolumn{2}{|c|}{ Total by age } & 21 & 57 & 56 & & \\
\hline
\end{tabular}

uninfected mice). In these cases, where analysis by ANOVA with negative binomial errors was not possible, the data were normalized by $\log (x+1)$ transformation, normal distribution of transformed data was confirmed by examination of the residuals and then analysed by GLIM with normal errors (for which the scaled deviance is distributed as F). When it was possible to reduce complex models to just limited significant effects, the results are given in the text as $\mathrm{F}$ values with associated probabilities and not in full ANOVA tables.

The negative binomial exponent $k$ was estimated using maximum likelihood procedure on a University of Nottingham PC program, based on the procedure described by Elliott (1977). The goodness of fit to the negative binomial distribution was tested by $\chi^{2}$.

\section{Results}

The mean rainfall data $(\mathrm{mm})$ recorded in July and August and for the first 14 days of each September, to coincide with the trapping period, are summarized in table 1 . This showed relatively wet September months in 1994 and 1995 preceded by extremely dry conditions in July/August where the mean rainfall for these months were $0.85 \mathrm{~mm}$ in 1994 and $0.37 \mathrm{~mm}$ in 1995 . In contrast, the dry months of September in 1996 and 1997 were preceded by wetter conditions in July and August with the mean rainfall for this period reaching $1.76 \mathrm{~mm}$ in 1996 and $2.17 \mathrm{~mm}$ in 1997.

A total of 134 A. sylvaticus, 91 male and 43 female mice was trapped over the 4-year period as summarized in table 2. Across all 4 years more male than female mice were examined and there was also significant variation in the age distribution of mice between years (table 3 , the year $\times$ age interaction).

\section{Overall prevalence and helminth species richness}

Table 4 summarizes the overall prevalence, range of infection and mean abundance of the nine species of helminths recovered across the 4 years of the study. One hundred and twenty three mice $(91.8 \%)$ harboured at least one of the nine helminths recorded and the frequency distribution is illustrated in fig. 1A. Mice with two and three helminths were the most common category and the widest range of species recorded in an individual mouse was six. The mean number of species per mouse (species richness of Montgomery \& Montgomery, 1989) was $2.4 \pm 0.11$, with little difference between the sexes (males $=2.4 \pm 0.14$, females $=2.3 \pm 0.18)$. However, there was a significant effect of year and a highly significant main effect of age, as well as a weak significant interaction between these factors (fig. 1B, table 5). Mice in the youngest age cohort harboured the fewest species of helminths and this was consistent across all 4 years. However, the mean number of species harboured by the older cohorts varied from year to year. In three of the years (1995, 1996 and 1997) there was a marginal reduction in the mean number of species recovered from age cohort 3 relative to age cohort 2 .

The most common species were the nematodes H. polygyrus and Syphacia stroma as in the majority of previous UK based studies. The least common were 
Table 3. Minimum sufficient maximum likelihood statistical models of factors affecting the prevalence of infection with the six most common helminth parasites in Apodemus sylvaticus.

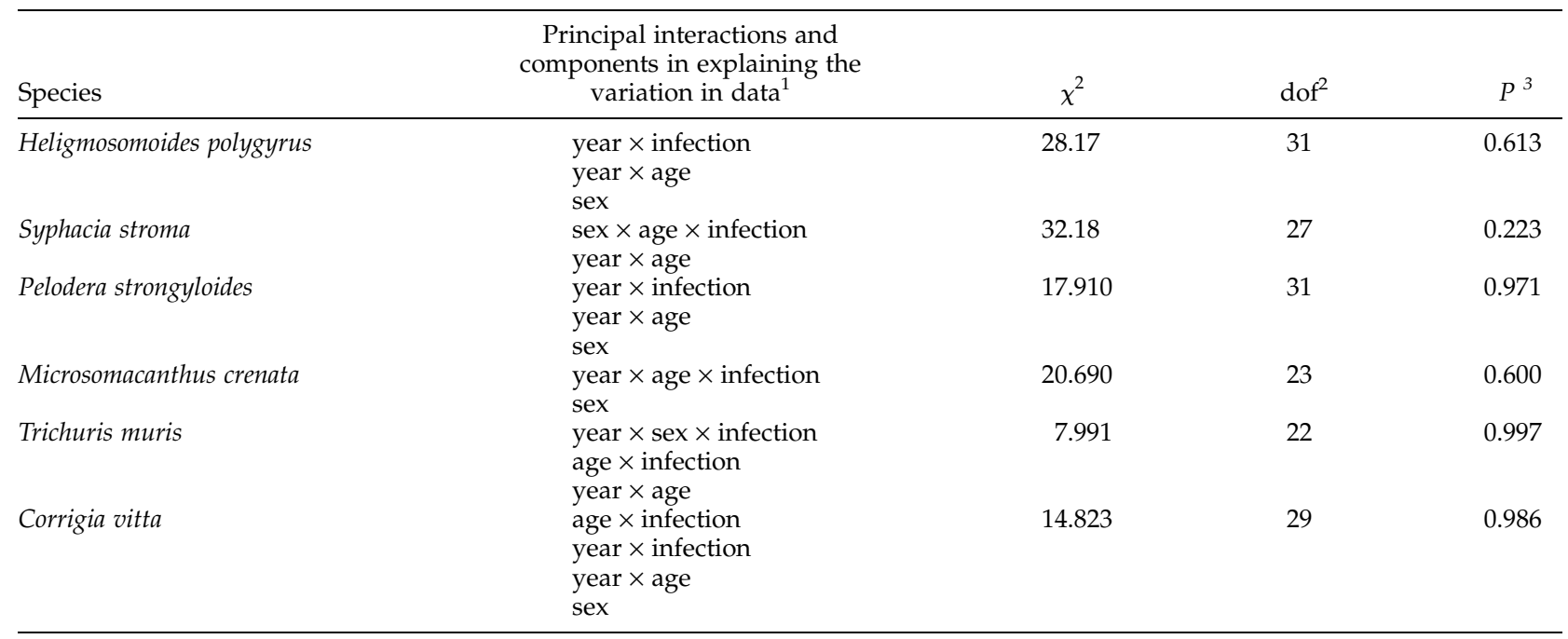

${ }^{1}$ Year - 4 levels 1994, 1995, 1996, 1997; age - 3 levels, age cohorts 1, 2 and 3; sex - 2 levels, males and females.

${ }^{2}$ Degrees of freedom.

${ }^{3}$ Probability that the data does not differ significantly from the minimum sufficient model described by the principal interactions and components.

Table 4. Prevalence, range of infection and mean abundance of helminths across the 4 years of the study by host sex and sexes combined.

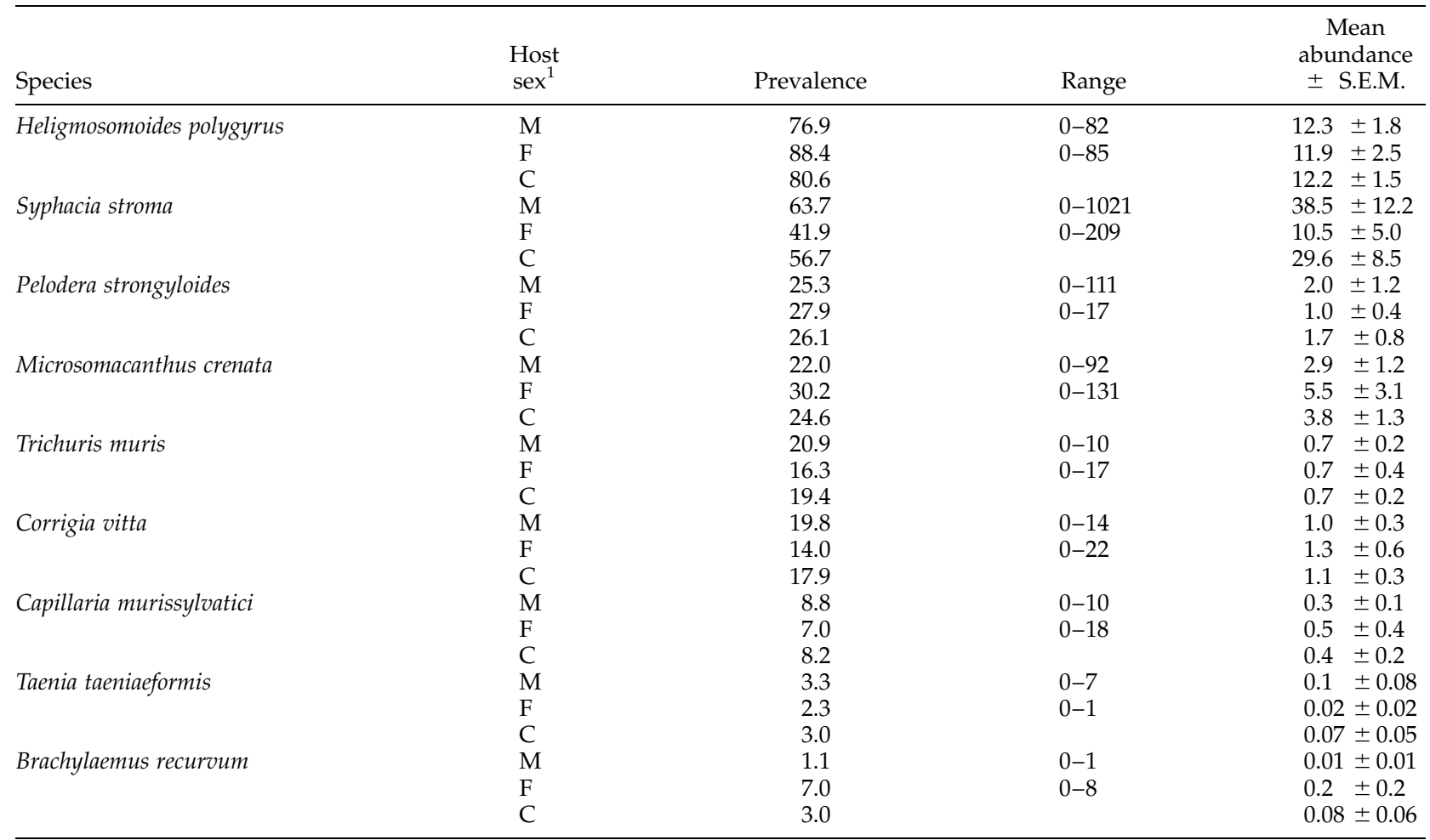

${ }^{1} \mathrm{M}$, male; F, female, $\mathrm{C}$, sexes combined.

For sample size see table 2 . 
Brachylaemus recuroum, Taenia taeniaeformis and Capillaria murissylvatici all showing prevalence $<10 \%$ and these latter species will not be considered further in statistical analysis of factors affecting the prevalence and abundance of infection.

\section{Heligmosomoides polygyrus}

Overall, 108 mice (80.6\%) were infected with H. polygyrus with a slightly higher prevalence among female mice compared with males (table 4). The minimum sufficient model (table 3 ) confirmed that there were significantly more males $(n=91)$ than females $(n=43$; see table 2) among the sampled mice (the sex component) but
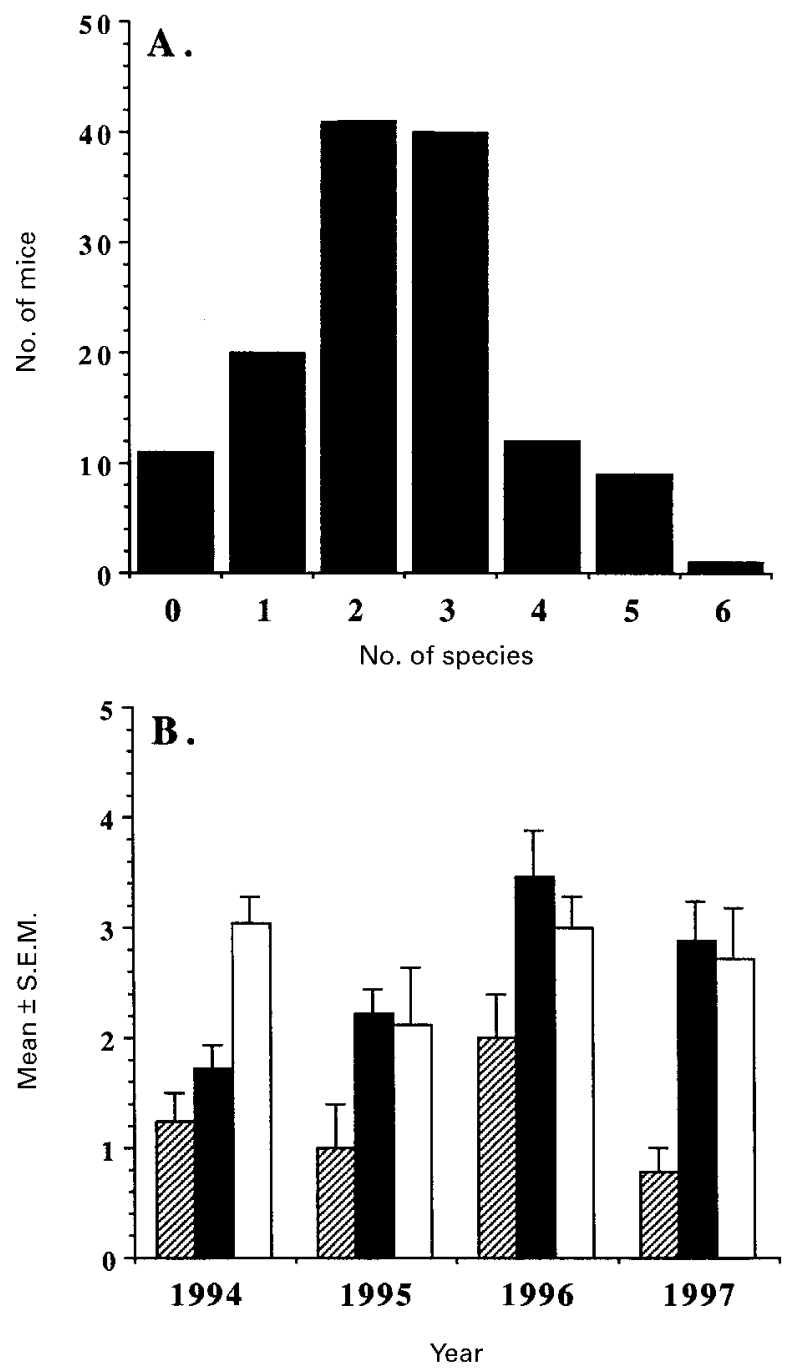

Fig. 1. A. Frequency distribution of Apodemus sylvaticus, according to number of helminth species harboured. B. Variation in species richness (mean number of helminth species harboured) by year of study and age of host (age cohort $1 囚$; age cohort $2 \mathbf{\square}$; age cohort $3 \square$ ) the absence of an interaction with the infection term indicated that the prevalence of infection with $H$. polygyrus did not vary significantly between the sexes. However, prevalence of infection varied significantly between the years (fig. 2A. table 3 , year $\times$ infection interaction), but not between age cohorts (there was no infection $\times$ age interaction). The year $\times$ age interaction indicated that the sample size of mice within specific age cohorts varied significantly from year to year (table 2).

The variance to mean ratio for $H$. polygyrus was 23.5 and $k=0.45 \pm 0.08\left(\chi^{2}=0.83, d f=4, P=0.93\right)$ indicating a good fit to the negative binomial distribution of this species in the host population. The mean abundance of $H$. polygyrus was $12.2 \pm 1.5$, with similar means for both sexes (table 4) and no significant difference between the sexes (table 6). However, there was a strong significant
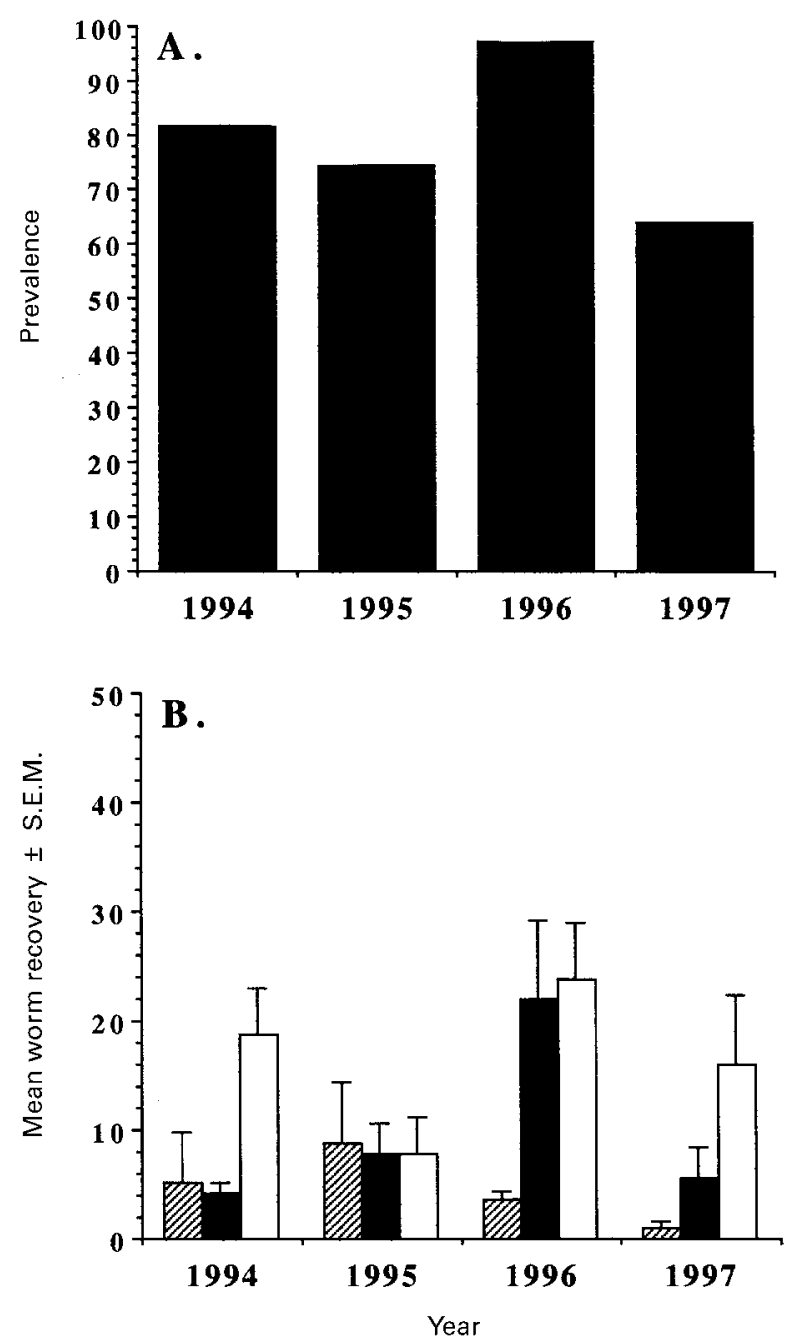

Fig. 2. A. Prevalence of Heligmosomoides polygyrus by year of study. B. Mean abundance of infection by age and year of study. For sample sizes see table 1 . Age cohort 1ש; age cohort $2 \mathbf{\square}$; age cohort $3 \square$. 
Table 5. Statistical analysis of the factors affecting variation in helminth species richness (number of helminth species harboured) of Apodemus sylvaticus by year, sex and age, through a 3-way ANOVA with normal errors.

\begin{tabular}{|c|c|c|c|c|c|}
\hline Source of variation & $\begin{array}{l}\text { Change in } \\
\text { deviance }^{1}\end{array}$ & $\begin{array}{l}\text { Degrees } \\
\text { of freedom }\end{array}$ & $\begin{array}{c}\text { Scale } \\
\text { parameter }\end{array}$ & $\begin{array}{c}\text { Scaled } \\
\text { deviance* }\end{array}$ & $P$ \\
\hline Age & 38.60 & 2 & 1.608 & 12.002 & $<0.001$ \\
\hline Year & 14.27 & 3 & 1.408 & 3.378 & $0.025>P>0.01$ \\
\hline Sex & 0.052 & 1 & 1.319 & 0.039 & NS \\
\hline Sex $\times$ age & 1.021 & 2 & 1.329 & 0.384 & NS \\
\hline Year $\times$ sex & 9.091 & 3 & 1.342 & 2.258 & NS \\
\hline Year $\times$ age & 17.54 & 6 & 1.301 & 2.247 & $0.05>P>0.025$ \\
\hline
\end{tabular}

The full model deviance was 137.33 with a scale parameter of 1.248 .

NS, Not significant.

${ }^{1}$ Change in deviance following the removal of the combination specified in 'source of variation' column from the full factorial model. We begin by removing the 3-way interaction, followed by the 2 -way interactions. The remaining main effects, however, were removed to assess the change in deviance but then replaced before proceeding further.

*Scaled deviance is a measure of the contribution of the factor specified under the column labelled 'source of variation' to explaining the variation in the data. It is calculated by fitting an analysis of variance with normal errors through GLIM and is distributed as F.

Table 6. Statistical analysis of the factors affecting variation in abundance of Heligmosomoides polygyrus in Apodemus sylvaticus by year, sex and age, through a 3-way ANOVA with negative binomial errors.

\begin{tabular}{lcccc}
\hline Source of variation & $\begin{array}{c}\text { Change in } \\
\text { deviance }^{1}\end{array}$ & $\begin{array}{c}\text { Degrees } \\
\text { of freedom }\end{array}$ & $\begin{array}{c}\text { Scale } \\
\text { parameter }\end{array}$ & $\begin{array}{c}\text { Scaled } \\
\text { deviance* }^{*}\end{array}$ \\
\hline Age & 434.0 & 2 & 20.55 & 21.119 \\
Year & 425.0 & 3 & 20.32 & 20.915 \\
Year $\times$ age & 351.0 & 6 & 17.48 & 20.080 \\
$\begin{array}{l}\text { Sex and all its } \\
\text { interactions }\end{array}$ & 238.5 & 12 & 15.46 & $<0.0005$ \\
\hline
\end{tabular}

The full model deviance was 1647.3 with a scale parameter of 14.98 .

NS, Not significant.

${ }^{1}$ Change in deviance following the removal of the combination specified in 'source of variation' column from the full factorial model. When we attempted to remove the 3 -way interaction (sex $\times$ age $\times$ year $)$ from the model the iterations diverged. We therefore removed sex and all of its interactions as the first step, followed by removal of the 2-way interaction. The remaining main effects, however, were removed to assess the change in deviance but then replaced before proceeding further.

*Scaled deviance is a measure of the contribution of the factor specified under the column labelled 'source of variation' to explaining the variation in the data. It is calculated by fitting an analysis of variance with negative binomial errors through GLIM and is distributed as $\chi^{2}$.

Table 7. Statistical analysis of the factors affecting variation in abundance of Syphacia stroma in Apodemus sylvaticus by year, sex and age, through a 3-way ANOVA with normal errors.

\begin{tabular}{|c|c|c|c|c|c|}
\hline Source of variation ${ }^{1}$ & $\begin{array}{l}\text { Change in } \\
\text { deviance }^{2}\end{array}$ & $\begin{array}{l}\text { Degrees } \\
\text { of freedom }\end{array}$ & $\begin{array}{c}\text { Scale } \\
\text { parameter }\end{array}$ & $\begin{array}{c}\text { Scaled } \\
\text { deviance* }\end{array}$ & $P$ \\
\hline Age & 20.24 & 2 & 2.931 & 3.453 & $0.05>\mathrm{P}>0.025$ \\
\hline Sex & 21.92 & 1 & 2.967 & 7.388 & $<0.01$ \\
\hline Sex $\times$ age & 3.472 & 2 & 2.818 & 0.616 & NS \\
\hline Year $\times$ age & 26.28 & 6 & 2.835 & 1.545 & NS \\
\hline Year $\times$ sex & 5.072 & 3 & 2.757 & 0.613 & NS \\
\hline
\end{tabular}

The full model deviance was 316.66 with a scale parameter of 2.80 .

NS, Not significant.

${ }^{1}$ Worm burden data were normalized by $\log (x+1)$ transformation because a negative binomial distribution could not be fitted to the data. ${ }^{2}$ Change in deviance following the removal of the combination specified in 'source of variation' column from the full factorial model. We begin by removing the 3-way interaction, followed by the 2-way interactions. The remaining main effects, however, were removed to assess the change in deviance but then replaced before proceeding further.

*Scaled deviance is a measure of the contribution of the factor specified under the column labelled 'source of variation' to explaining the variation in the data. It is calculated by fitting an analysis of variance with normal errors through GLIM and is distributed as F. 
effect of age and year, and a significant interaction between these factors (table 6). The data are illustrated in fig. 2B, with sexes combined since no significant difference was detected. It can be seen that the mean worm burden increased from the youngest mice (age cohort 1) through the intermediate (age cohort 2) to the older mice (age cohort 3) in 2 of the 4 years sampled (1996 and 1997). However, the interaction arose because there was no apparent change in worm burden with age in 1995, and in 1996 the rise occurred between age cohort 1 and 2, whereas in both 1994 and 1997 it occurred between age cohort 2 and 3 .

\section{Syphacia stroma}

Syphacia stroma was the second most common species with 76 mice $(56.7 \%)$ carrying the parasite (table 4 ) but there was some variation in prevalence between the years
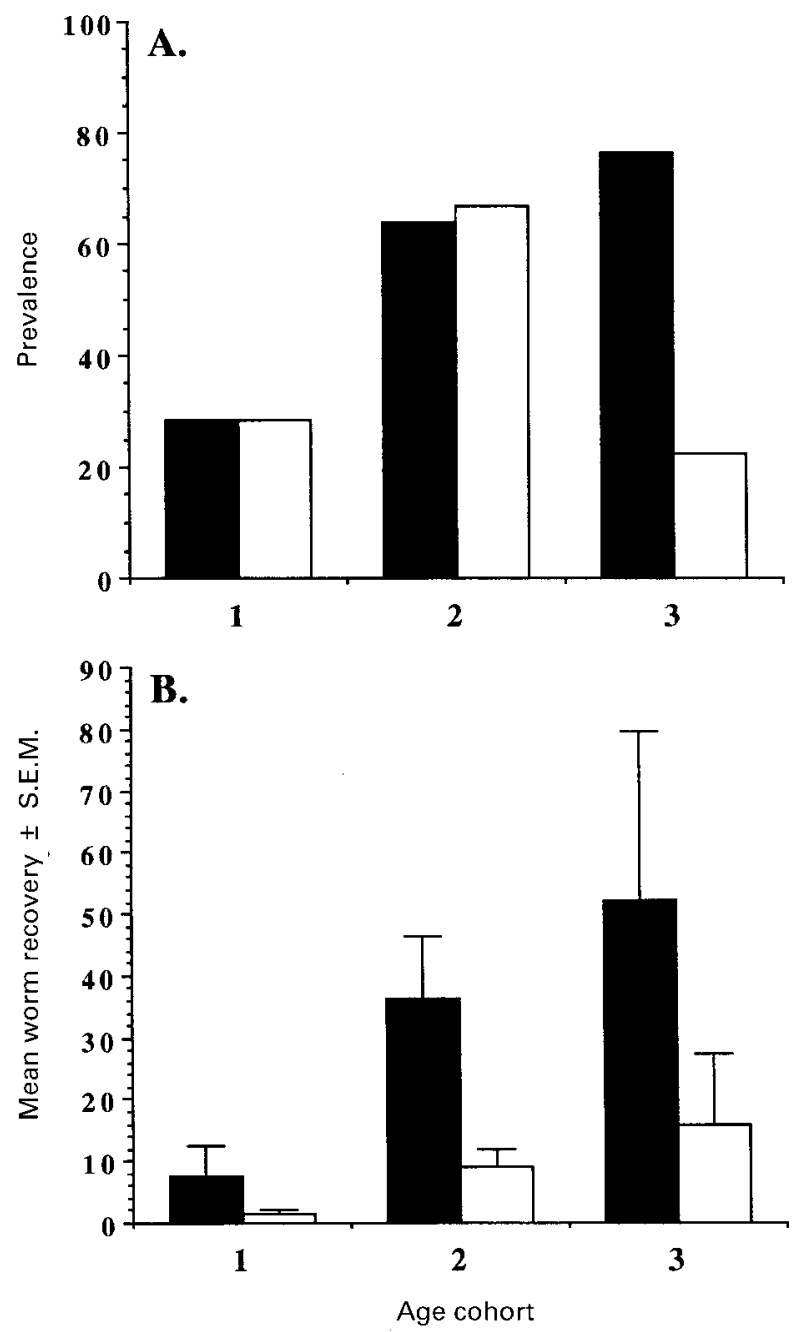

Fig. 3. A. Prevalence of Syphacia stroma by host sex and age (no significant year effect was found). B. Mean abundance of infection by host sex and age. For sample sizes see table 1 . Males $\boldsymbol{\square}$, females $\square$.
(1994, 47.7\%; 1995, 71.0\%; 1996, 61.8\%; 1997, 48.0\%) although this was not significant (table 3, no year $\times$ infection interaction). A significant 3-way interaction between sex, age and infection was identified (table 3), indicating that the prevalence of infection with $S$. stroma differed between the sexes in relation to age. Prevalence increased between age cohorts 1 and 2 in both sexes (fig. $3 \mathrm{~A})$, then rose further in males to age cohort 3 whilst in female mice the prevalence fell.

The variance to mean ratio was 328.7 and $k=0.176 \pm$ $0.027\left(\chi^{2}=3.08, d f=3, P=0.38\right)$ indicating a significant but poor fit to the negative binomial distribution. Analysis of abundance by GLIM, using ANOVA with normal errors on transformed data, revealed that there were no compounding interactions and only the main effects of age and sex were significant (table 7). Thus the intensity of infection increased with age in both male and female mice (fig. 3B), but was markedly higher throughout in males.

\section{Pelodera strongyloides}

Thirty five mice $(26.1 \%)$ carried P. strongyloides with an almost indistinguishable prevalence between the sexes (table 4 , and no sex $\times$ infection interaction in table 3 ). However, prevalence of infection varied significantly between years (fig. 4A, table 3 , the year $\times$ infection interaction) dropping sharply in 1995 to 3.2\%, when only one of the 31 mice sampled in that year carried $P$. strongyloides. The variance to mean ratio was 56.3 and $k=0.106 \pm 0.021\left(\chi^{2}=1.05, d f=2, P=0.597\right)$ indicating a good fit to the negative binomial distribution. However, the dataset comprised one extreme outrider, 34 of the 35 infected mice harbouring 1-17 larvae but one animal had 111. This, and the low number of infected animals, precluded use of ANOVA with negative binomial errors in GLIM. Analysis of abundance of infection by GLIM, through ANOVA with normal errors following log $(x+1)$ transformation of data, revealed that the only significant effect was that of year $\left(F_{3,130}=3.449,0.025>P>0.01\right)$. These data are illustrated in fig. 4B.

\section{Microsomacanthus crenata}

Thirty three mice $(24.6 \%)$ were infected with $M$. crenata (table 4) with a slightly higher (not significant) prevalence among female mice (table 3 , no sex $\times$ infection interaction). The 3-way interaction between year, age and infection (table 3), indicated that not only were there significant differences between the sample size of different age cohorts between the years, but also that these varied in relation to prevalence of infection. This is illustrated in fig. 5A, which shows that none of the mice in the youngest age cohort harboured $M$. crenata across all 4 years. However, prevalence in the older age cohorts showed some marked changes rising to well above $20 \%$ in age cohort 3 in 1994 and age cohort 2 in 1996. Otherwise there was little difference between these age cohorts.

The variance to mean ratio was 60.6 and $k=0.07 \pm 0.0138$ $\left(\chi^{2}=1.91, d f=1, P=0.163\right)$ indicating a significant but moderate fit to the negative binomial distribution. The abundance data were therefore analysed, following log $(x+1)$ transformation, by GLIM with normal errors and 
the results revealed that the age $\times$ year interaction was significant $\left(F_{6,125}=2.613,0.025>P>0.01\right)$. There was also a weak but significant main effect of host age $\left(F_{2,129}=3.08,0.05>P>0.025\right)$. Figure 5B shows that the age effect arose because age cohort 1 mice did not carry this parasite and age cohort 3 mice always harboured heavier infections than age cohort 2. However, there was some between-year variation in the mean abundance of infection harboured by mice in age cohorts 2 and 3. In particular in 1994, the mean worm burden in age cohort 3 was very high because of the generally high prevalence in that year but also because two mice harboured 131 and 54 worms, respectively. In contrast in 1996 whilst the prevalence in age cohort 2 was also high, the mean abundance was lower.

\section{Trichuris muris}

Twenty six mice $(19.4 \%)$ were infected with T. muris
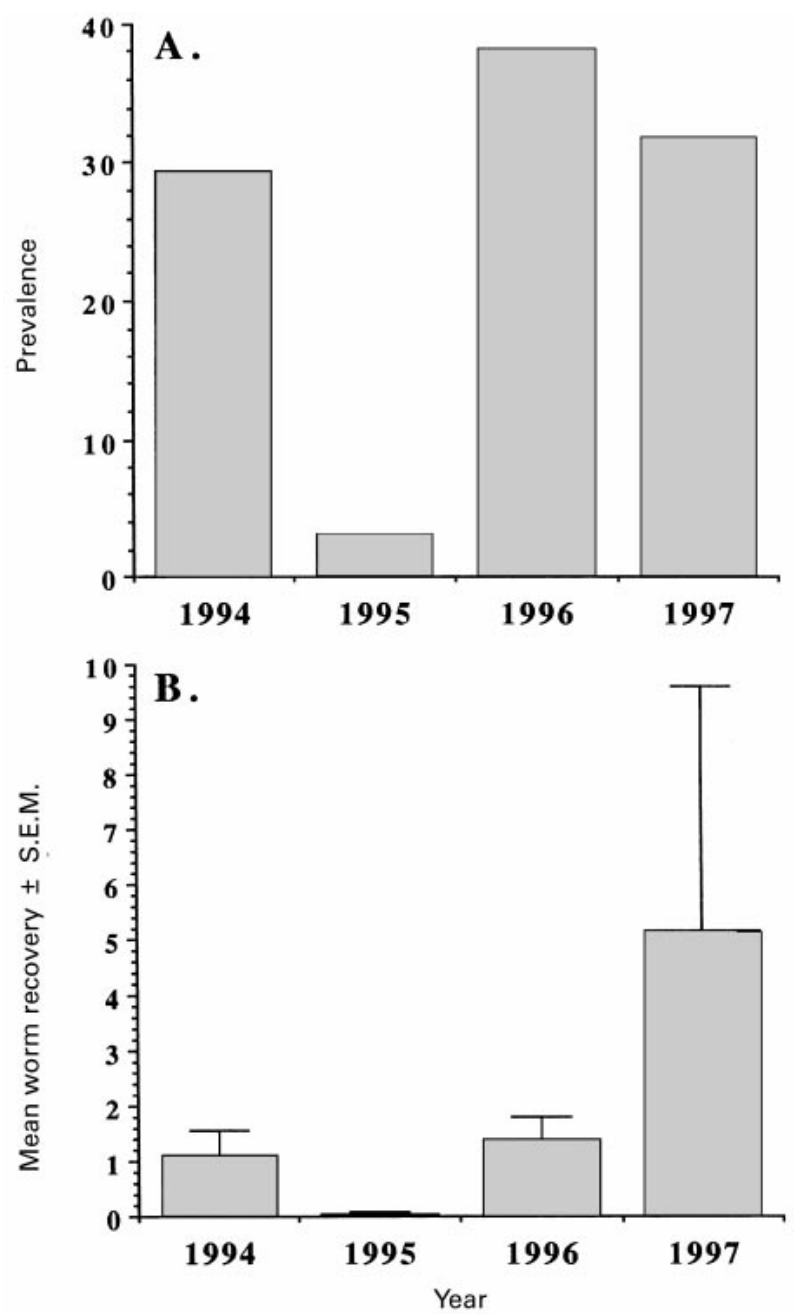

Fig. 4. A. Prevalence of Pelodera strongyloides by year of study. B. Mean abundance of infection by year of study (no significant effects of sex or age were detected). For sample sizes see table 1. (table 4). The 3-way interaction (table 3) indicated significant variation in prevalence between the sexes and across years (fig. 6A). In 1994 and 1997 prevalence was high among males but low in females, whereas in 1996 females showed higher prevalence. However, there was also an independent effect of age (the age $\times$ infection interaction) on the prevalence of T. muris as illustrated in fig. $6 \mathrm{~B}$ with a clear increase in prevalence with age across the three age cohorts. The variance to mean ratio was 6.5 and $k=0.108 \pm 0.027\left(\chi^{2}=0.01, d f=1, P=0.913\right)$ indicating a very good fit to the negative binomial distribution but the data could not be processed by GLIM with negative binomial errors because of absence of infection in some subsets of data. However, analysis of the
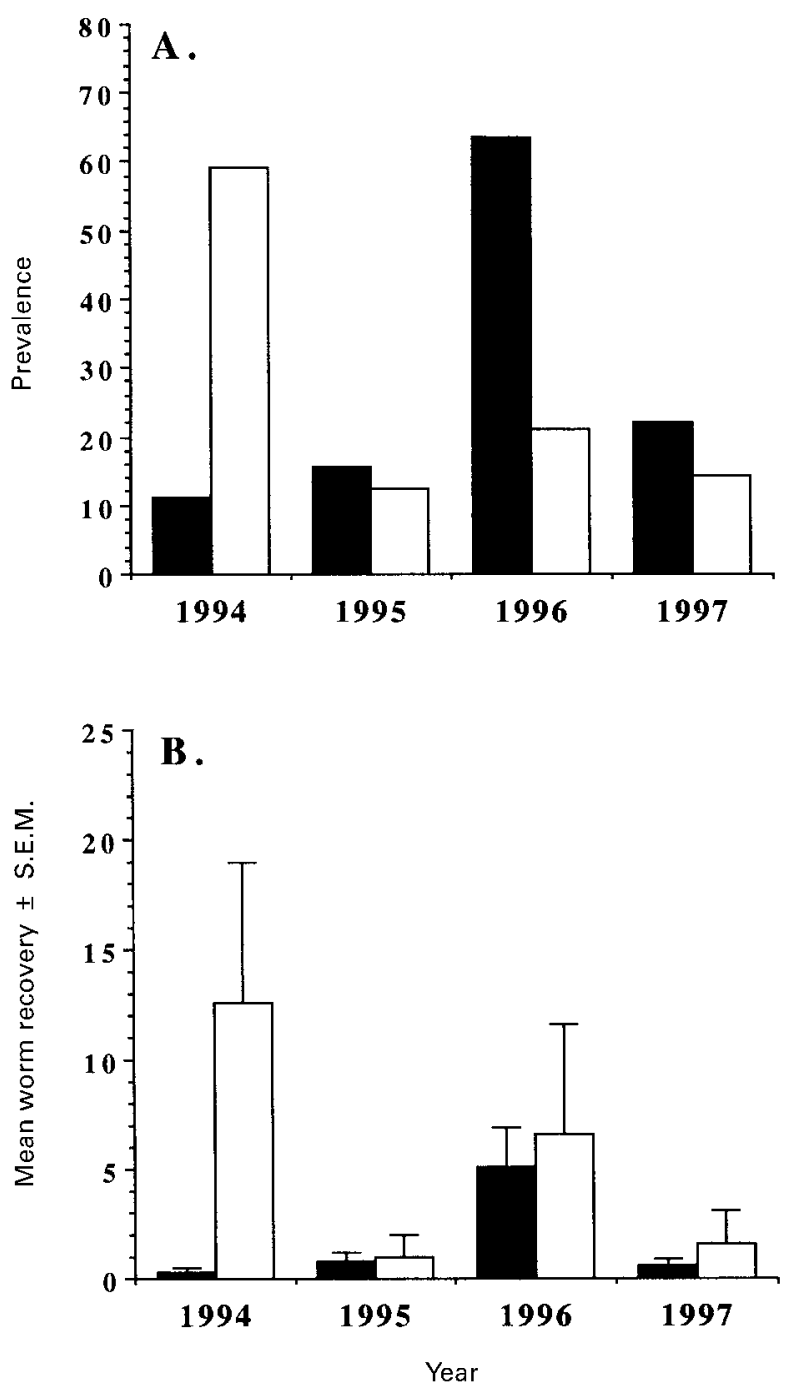

Fig. 5. A. Prevalence of Microsomacanthus crenata by age and year of study. B. Mean abundance of infection by age and year of study (no significant sex effect was detected). For sample sizes see table 1. Age cohort $2 \mathbf{\square}$; age cohort $3 \square$. Mice in age cohort 1 were not infected. 
abundance of infection, after $\log (x+1)$ transformation of data, by GLIM with normal errors showed that only the main effect of age was significant (fig. 6C. $F_{3,130}=2.098$, $0.025>P>0.01$ ).

\section{Corrigia vitta}

Twenty four mice $(17.9 \%)$ were infected with C. vitta (table 4). Two significant, but independent, effects on prevalence were identified (table 3): that of year and host age. Figure $7 \mathrm{~B}$ shows that there appeared to be a cycle of
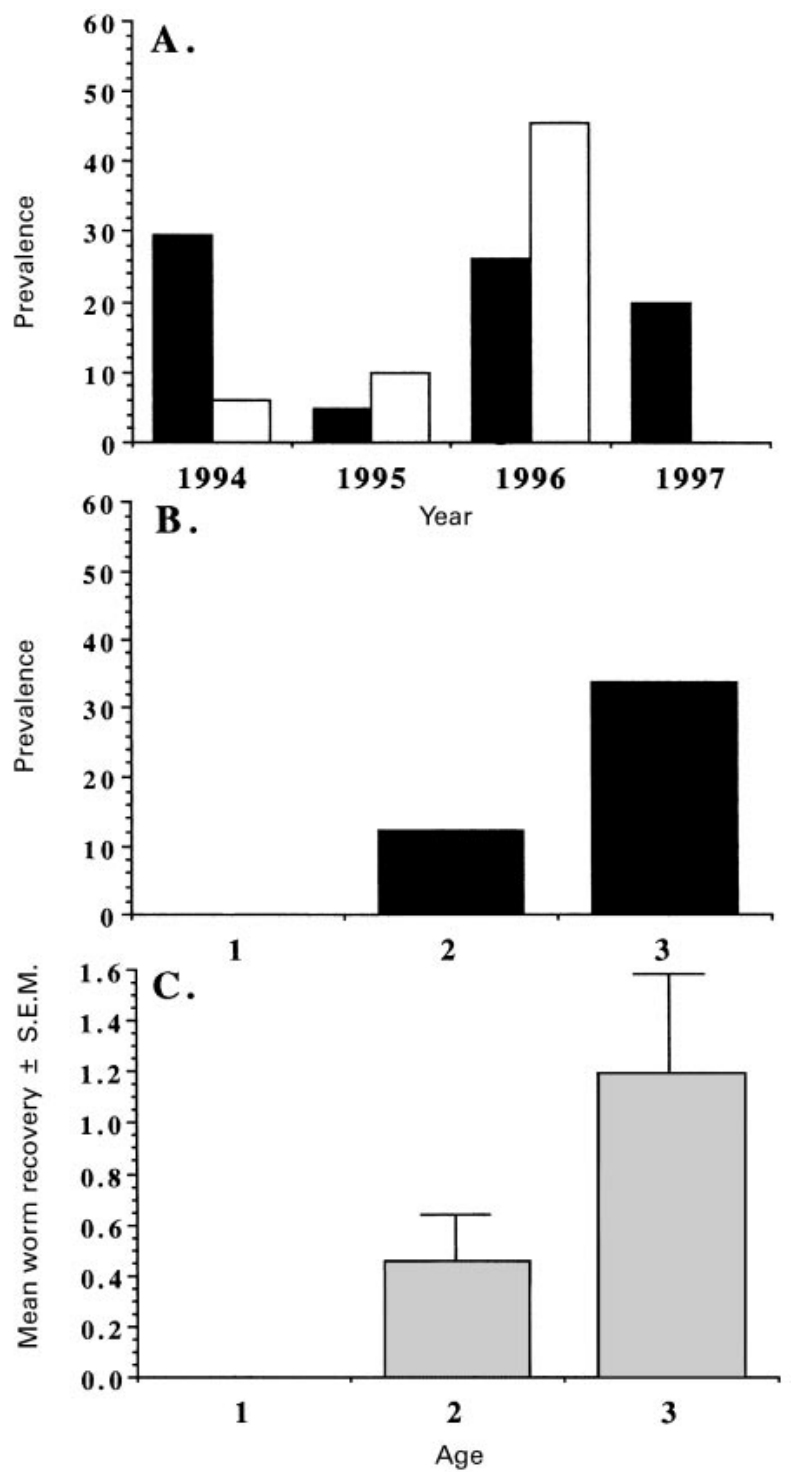

Fig. 6. A. Prevalence of Trichuris muris by host sex and year of study. Males $\mathbf{\square}$; females $\square$. B. Prevalence of T. muris in relation to host age. C. Mean abundance of infection by age (no significant effects of host sex nor year of study were detected). For sample sizes see table 1. increasing/decreasing prevalence with peaks in 1995 and 1997. The youngest mice were not infected while age cohorts 2 and 3 showed very similar prevalence (fig. 7A) . The variance to mean ratio was 9.4 and $k=0.074 \pm 0.017$ $\left(\chi^{2}=1.51, d f=1, P=0.216\right)$ indicating a significant but moderate fit to the negative binomial distribution, so for this reason and because of absence of infection in some subsets of data, analysis of abundance of infection through GLIM with negative binomial errors was not successful. However, following $\log (x+1)$ transformation of data and analysis by GLIM with normal errors, no significant interactions were detected and only the main effects of year $\left(F_{3,130}=4.04,0.01>P>0.005\right)$ and age $\left(F_{2,129}=4.451,0.025>P>0.01\right)$ were significant (fig. $\left.7 \mathrm{C}\right)$.

\section{Discussion}

Wild animals, living naturally in the ecosystem, vary in the range and diversity of parasites which they harbour at any particular time. This between-host variation in parasite burdens arises through numerous factors, some influencing susceptibility/resistance to infection independently, others interacting at a variety of levels. Such factors can be broadly divided into two classes: (i) intrinsic factors (i.e. those arising from within the host and varying between individual animals, e.g. age, sex, hormonal differences, genetic variation in susceptibility/ resistance to infection, exposure to infection, etc.); and (ii) extrinsic factors (those arising from variation in the ecosystem of the host, e.g. time of year, between-year differences in seasons, difference in quality of habitat, contamination levels with parasite transmission stages, density of intermediate hosts, etc.). Teasing apart the relative importance of these factors in explaining patterns of infection is problematic because subjective interpretation of trends arising from summary statistics can be misleading and because apparent trends between a particular parasite burden and a selected variable/ factor may arise indirectly or artifactually through omission to consider all the available information in the analysis.

In this paper we employed statistical methods to tease apart the relative importance of one extrinsic factor (year of sampling) and two intrinsic factors (age and sex) in determining parasite burdens in Apodemus sylvaticus. In order to limit the range of factors in the analysis, we sampled field mouse populations from the same site only during September, thereby avoiding the added complication of including site and season of the year in the analysis. September is a time when we could reasonably expect the population of mice to include all age ranges from young juveniles to older adults and a diversity of parasite species peaking in intensity following exposure during the preceding warm summer months when transmission of most species would have been optimal. Earlier studies have shown that parasite burdens increase in field mice living in our study site at this time of year (Abu Madi et al., 1998; unpublished observations).

Despite our attempts to produce balanced data-sets for the analysis, our total sample of animals yielded more male than female mice, as has been found in other studies (Abu-Madi et al., 1998). The most likely explanation for 
this is that, September being still within the breeding season of $A$. sylvaticus, female mice may have been less active foragers than males while suckling young, and hence less likely to be trapped (Morris, personal communication). We also had unbalanced data-sets with respect to the proportion of mice among the three age cohorts. For these reasons, any analysis of parasite burdens with respect to between-year variation had to take into account and control for host sex and age.

Although nine species of helminths were identified in the host population during the 4 years of the study, the
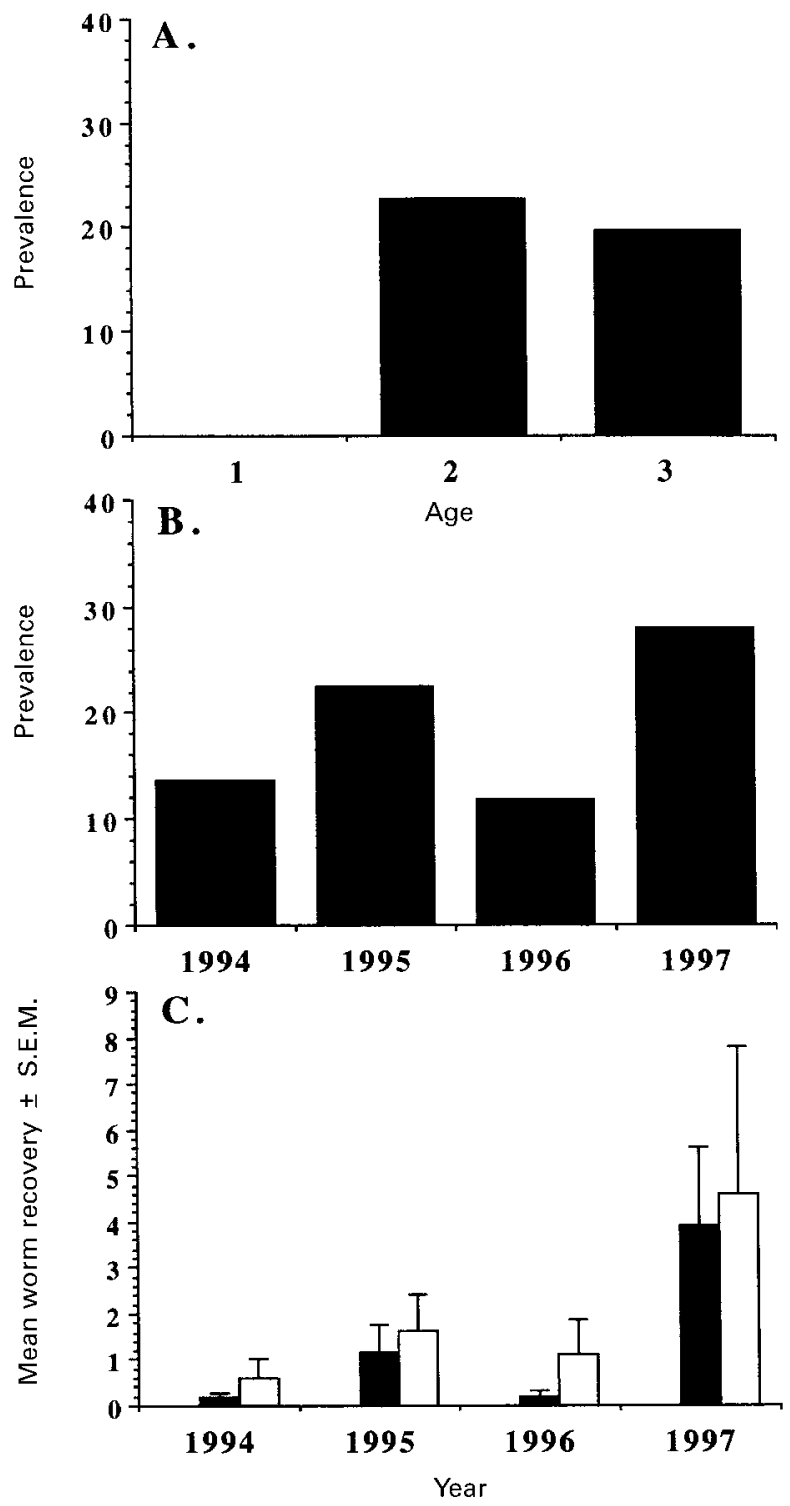

Fig. 7. A. Prevalence of Corrigia vitta by host age (A) and year of study (B). C. Mean abundance of infection by age and year of study (no significant effect of host sex was detected). For sample sizes see table 1 . Age cohort $2 \mathbf{\square}$; age cohort $3 \square$. Mice in age cohort 1 were not infected. most that any one mouse carried was six species (fig. 1), much in agreement with Tenora's (1967) data on 11 rodents inhabiting the Rohacska Dolina valley, although in that study the maximum number of helminths carried by $A$. flavicollis was three and by $A$. terrestris just one. Interestingly, the average number of species harboured per mouse in our total population was 2.4 species (species richness of Montgomery \& Montgomery, 1989), with $60.5 \%$ of the sample carrying either two or three helminth species, much in line with the data of Montgomery \& Montgomery (1989). Whilst there was no difference between the sexes in this context, the effect of age was pronounced, but variable between the years. As expected, in all years the lowest average mean number of species was found among the juveniles but then appeared to stabilize in age cohorts 2 and 3, although 1994 was exceptional in so far as the highest mean number of species was harboured by age cohort 3. Therefore helminth species richness increased from juvenile through to adult, in step with increased foraging, total duration of exposure and accumulating parasite burdens. These data parallel closely those reported by Montgomery \& Montgomery (1989), who found a significant increase in species richness with increasing age across seven age cohorts of $A$. sylvaticus in Northern Ireland.

As in other UK and Eire based studies of helminths in A. sylvaticus, $H$. polygyrus was clearly one of the two dominant species (Elton et al., 1931; Sharpe, 1964; Lewis, 1968; Montgomery \& Montgomery 1990), affecting over $80 \%$ of the host population. Surprisingly, there was no significant age effect on prevalence when other factors, sex and year, were taken into account, an apparent increasing prevalence with increasing age (61.9, 78.9, $89.3 \%$ age cohorts $1-3$, respectively), arising indirectly through variation between the years in the prevalence among the age cohorts. However, prevalence varied significantly between the years (see also Elton et al., 1931) and mice in all 4 years showed relatively high prevalence with this species when compared to other helminths. The relatively small, but significant, fluctuations between the years confirmed that prevalence of H. polygyrus was maintained within limits close to $80 \%$. This accords with data from Clethrionomys glareolus (Kisielewska, 1970) among which the prevalence of the related species Heligmosomoides/ Heligmosomum spp. varied in the range $40-70 \%$ over an 8 -year period.

Seasonal cycles in the abundance of $H$. polygyrus are well established (O'Sullivan et al., 1984; Abu-Madi et al., 1998) and variations in these cycles between years have likewise been reported (Montgomery \& Montgomery, 1988), as have age-related increases in abundance (Elton et al., 1931; Lewis, 1968; Kisielewska, 1971; Gregory, 1992; Gregory et al., 1992), but the relative importance of the age effect in relation to the year effect has not been evaluated. Our analysis established conclusively that the age effect was the dominant factor affecting abundance of $H$. polygyrus in September in our study site, although in some years it was compounded by some unexpected variations to the general pattern of increasing worm burdens with increasing age. Clearly, 1995 was an exceptional year, when abundance appeared to be fairly uniform across all three age cohorts, but, in comparison with other years, infections were heavier among age 
cohort 1 and lower in age cohort 3. Therefore, transmission to juvenile mice was more efficient than in other years and, coincidentally, September rainfall was the heaviest in that year. However, the adult mice harboured lower worm burdens than expected suggesting that the extremely dry conditions in July and August 1995, with mean monthly rainfall of just $0.68 \mathrm{~mm}$ and $0.05 \mathrm{~mm}$, respectively, had not been conducive for larval survival and hence transmission. Similarly the heavier infections in both age cohorts 2 and 3 in 1996 are likely explained by the relatively wet August in that year. Consistent with some earlier studies (Gregory, 1992; Gregory et al., 1992; Abu-Madi et al., 1998) but contrasting with others (Lewis, 1968) male and female mice carried similar H. polygyrus worm burdens.

Another parasite for which between-year variation in abundance was marked was C. vitta, and although age also accounted for some of the variation, the year effect was marginally stronger than the age effect. There were no complicating interactions so these two factors operated independently of each other. Worm burdens were confined to the older age cohorts and in these showed an increase in mean worm burden from age cohort 2 to 3, consistent with the idea that the longer the exposure the heavier the worm burdens. A marked age-related, but not-sex related, difference in abundance of this species has been reported previously (Lewis, 1968). Whilst significant, the between-year variation showed no clear pattern, although a loose trend of increasing mean abundance across the study was apparent, with the heaviest worm burdens detected in the final year of the work in 1997 (fig. 8c). Montgomery \& Montgomery (1988) reported seasonal cycles in abundance of infection with $C$. vitta, with peak worm burdens in late winter (February to March), as was found also by Langley \& Fairley (1982) in Eire. The former authors reported that in some sites the parasite was absent from mice in particular years. It is therefore, possible that the between-year variation in our study in September, represented variation in the tail end of declining worm burdens following peak abundance in earlier months. However, O'Sullivan et al. (1984) found a bimodal peak prevalence coinciding with September and March and the pattern of change in prevalence reported by Lewis (1968) suggested that in Wales the parasite was encountered throughout the year. Taken together, these studies indicate that the interaction between seasonal occurrence of C. vitta and location (study site) is complex, unpredictable and dependent on the seasonal availability of the arthropod intermediate hosts, although the precise details of the life cycle of C. vitta are still unknown.

Of the two species of cestodes, Microsomacanthus crenata (= Hymenolepis murissylvatici (Rudolphi, 1819) = Variolepis crenata (Goeze, 1782)) was the more common. It may be worth first clarifying some of the name changes associated with this species since the original description by Rudolphi (1819). Prokopic (1967) considered the murine species $H$. muris-sylvatici a synonym of the bird parasite Passerilepis crenata, but since then Passerilepis has been incorporated into the genus Microsomacanthus (R. Bray, personal communication, 1993, 1998; Khalil et al., 1994). For this parasite, there was no clear dominant factor affecting worm burdens. The main effect of age was weakly significant and the year $\times$ age interaction indicated that the relationship between age cohorts was not predictable but varied from year to year. The youngest age cohort did not harbour this species in any of the years of the study, most likely because of insufficient opportunity to feed on the flea intermediate hosts, species of which belong to the genus Ctenophthalmus (Lewis, 1987). Among the older cohorts, the years 1994 and 1996 were clearly exceptional. In 1994, it was cohort 3 which showed high prevalence and harboured intense infections, the latter arising because two mice harboured relatively high worm burdens (131 and 54, respectively). In 1996, cohort 2 showed high prevalence but abundance was not as high as in 1994 because the two highest worm burdens were only 28 and 92 worms. The high values for mean abundance are unusual for tapeworms, occurring in only 2 of the 4 years and each time in just one age cohort. This may be a chance occurrence, but could likewise arise if the parasite were to have been aggregated in its intermediate hosts in those particular years, for example if fleas harbouring the cycticercoids were to have been more common around some burrows than others.

The final parasite to show significant between-year variation was $P$. strongyloides, a seldom-reported species although it has been documented previously from our site (Hominick \& Aston, 1981). In contrast to the earlier species, the between-year variation for this species was not compounded by other factors. Quite clearly 1995 was a year in which few worms were recovered but was followed by increasing abundance in the two subsequent years. September 1995 was in fact the wettest month of the study and since the stage harboured by mice is the dauer larva (a stage considered to resort to transport hosts mainly when environmental conditions are unfavourable for the continuation of the free-living existence) the low prevalence in 1995 is compatible with the idea that the larvae had returned to the soil, stimulated by the moist conditions prevailing in September 1995, in contrast to the extremely dry conditions in 1996 and 1997, when the larvae remained in the mouse hosts.

Neither of the two remaining species analysed through our statistical models showed between-year variation but in each case abundance was influenced by intrinsic factors. Syphacia stroma was the second of the two most common species as found in earlier studies in the UK (Sharpe, 1964; Lewis, 1968; Montgomery \& Montgomery, 1988). In our study site, this species was stable from one year to the next, in contrast to Elton et al. (1931) who found a marked difference in prevalence between two successive winter periods. However, long-term stability has been reported with other species of Syphacia, e.g. S. obvelata (but more likely S. petrusewiczi Bernard, 1960) by Kisielewska in C. glareolus (1970), although in Białowieża prevalence was very low throughout the 9 -year period $(<11 \%)$. The most important factors determining infection with $S$. stroma in our study were host age and sex and, of these, host sex was the stronger effect. Earlier workers reported weak sex-related differences in abundance (Lewis, 1968) and prevalence (Sharpe, 1964; Langley \& Fairley, 1982) with this species but differed with respect to age-related changes (no agerelated change in prevalence or abundance, Lewis, 1968; moderate age-related changes in prevalence, Langley \& Fairley, 1982; marked age-related changes in prevalence, 
Elton et al., 1931). In the present study, however, mean abundance increased with age in both sexes but did so at different rates, more rapidly in males compared with females. The age related increase suggested greater or more prolonged exposure with age and that, in the field, this species causes chronic infections. Kisiewelska et al. (1973) and Kisielewska (1971) found that S. obvelata (possibly S. nigeriana (Baylis, 1928)) increased from juvenile to young adult cohorts but then declined among older voles. Our data only showed a fall in prevalence among older females, much as reported by Elton et al. (1931), but not in mean worm burdens. The sex bias could have arisen artifactually through a combination of the unusual distribution of this parasite among the host population (significant but poor fit to negative binomial) and the smaller sample size of females compared with males but we considered this to be unlikely. It is interesting to note that among the 11 heaviest worm burdens with S. stroma (range 104-258 with one mouse carrying 1021 worms), only one was female (209 worms and age cohort 3). Moreover, the statistical analysis of prevalence controlled for sample size and the GLIM analysis was very clear in its outcome. In our view, it is more likely that the sex effect reflected differences between the sexes in exposure (perhaps more contact between competing males (Syphacia spp. are spread by contact and transfer of embryonated eggs on fur)) or differences in immunocompetence. The later might be applicable to non-breeding animals, but females in breeding condition are likely to be pregnant and/or lactating for most of the summer/autumn seasons and hence we would expect them to be more immunodepressed than males with resultant heavier worm burdens.

Trichuris muris was only found in $19.4 \%$ of the mouse population, a lower prevalence compared with O'Sullivan et al. (1984) in Eire (48\%) but similar to the top range $(1.3-32.3 \%)$ reported by Montgomery \& Montgomery (1988) from Northern Ireland. The occurrence of the parasite regularly in at least some mice in September contrasts with Montgomery \& Montgomery (1988) who only detected this species in the late winter period (January-April, exceptionally longer) but never in September. Like M. crenata, in our study T. muris were only encountered in age cohorts 2 and 3 but in this species there was a significant main effect of age, uncomplicated by variation between years and by host sex. No sex effect and a similar marked age effect were also reported by O'Sullivan et al. (1984) for prevalence of infection with this parasite. Trichuris muris takes 5 weeks to become adult, eggs first appearing in host faeces 32 days after infection (Behnke et al., 1984) and therefore, it is not surprising that no worms were found in the youngest mice and that worm burdens increased with age. Low numbers of worms can survive for a long time in mice (Behnke \& Wakelin, 1973), despite the immunogenicity of the parasite, because such worm burdens tend to polarize the host response towards the non-protective Th- 1 type response, resulting in chronic infections. (Bancroft et al., 1994). The significant sex $\times$ year interaction in prevalence arose only because of the varying proportions of male and female mice harbouring worms from one year to the next. This did not seem to follow a discernible pattern although in 1995, the wettest year, prevalence was the lowest.
The remaining three species of helminths detected were rare and infected fewer than $10 \%$ of the hosts, making any further analysis impossible. All three have been regularly reported from rodents in other surveys, and all have been previously recorded in the UK.

It is also interesting to compare across the six species which were amenable to quantitative analysis. In five of the species, significant differences in prevalence and/or abundance of infection were detected between the 4 years of the study. For four of these species (H. polygyrus, P. strongyloides, M. crenata, and T. muris ) 1995 was a year of relatively low prevalence and/or intensity and 1996 was a peak year followed in each case by some reduction in 1997. Corrigia vitta showed an exact opposite trend, with peak infections in 1995 and 1997 and lows in 1994 and 1996 and this is likely to be related to the spatial distribution of the intermediate hosts. The only species which did not show between-year variation was S. stroma which, interestingly, is the only species which is spread by contact transmission.

Host age influenced prevalence and/or abundance of infection in five of the species (H. polygyrus, S. stroma, M. crenata, T. muris and C. vitta), as expected from increasing opportunity for contact with the transmission stages (intermediate hosts in two cases: M. crenata and C. vitta), and in virtually all cases the trend was for fewest worms in age cohort 1 and most in 3. Only in 1995, in mice with $H$. polygyrus, was this pattern reversed and the underlying reasons were considered earlier. Pelodera strongyloides was the only species which seemed to infect all age cohorts without preference, because it is a facultative parasite seeking out any available cohort of A. sylvaticus to avoid extreme environmental conditions.

Perhaps surprisingly, a sex difference was only identified in the case of one species, S. stroma. This argues in favour of exposure as an important determinant of sex-linked susceptibility to this species, perhaps associated with the unique method of transmission, since if immunodepression, associated with hormonal and/or immunological factors, was involved male mice should have harboured heavier worm burdens with other species, some of which are more pathogenic, invasive and immunogenic compared with pinworms.

Host density is clearly a factor in influencing the prevalence and abundance of infections in mammals, as recently shown by Arnebrg et al. (1998) who reported a positive correlation between host population density and parasite abundance in gastrointestinal strongylid nematodes from 19 mammalian species. Therefore larger samples of wood mice than those examined in the present study would need to be analysed to confirm whether or not host density is a determinant of abundance in the parasite communities of $A$. sylvaticus in our study site.

In conclusion, our analysis has identified the dominant factors, among those we recorded, affecting the prevalence and abundance of infection with six of the common helminth parasites of $A$. sylvaticus. As predicted from other studies, pronounced between-year differences in the prevalence and abundance were detected but the species differed in the degree to which the between-year effect was compounded by host age and sex and the pattern of the variation across the 4 years: four species showed broadly similar trends increasing/decreasing in 
the same years and one opposite, but each interacted in a different way with the two intrinsic factors. Our analysis emphasizes the need for carefully controlled statistical procedures, in aiding the interpretation and the prioritization of the factors affecting worm burdens in wild rodents.

\section{Acknowledgements}

We acknowledge support from the University of Malaya through the award of a scholarship to NSMZ. We also thank Rosemary Doran and Neil Morley for technical assistance and Paul Nicholas and Jim Culverhouse for recording the rainfall data.

\section{References}

Abu-Madi, M.A., Behnke, J.M., Lewis, J.W. \& Gilbert, F.S. (1998) Descriptive epidemiology of Heligmosomoides polygyrus in Apodemus sylvaticus from three contrasting habitats in south-east England. Journal of Helminthology 72, 93-100.

Arneberg P., Skorping A., Grenfell B. \& Read A.F. (1998) Host densities as determinants of abundance in parasite communities. Proceedings of the Royal Society of London, $B$ 265, 1283-1289.

Bancroft, A.J., Else, K.J. \& Grencis, R.K. (1994) Low-level infection with Trichuris muris significantly affects the polarization of the CD4 response. European Journal of Immunology 24, 3113-3118.

Behnke, J.M. \& Wakelin, D. (1973) The survival of Trichuris muris in wild populations of its natural hosts. Parasitology 67, 157-164.

Behnke, J.M., Ali, N.M.H. \& Jenkins, S.N. (1984) Survival to patency of low level infections with Trichuris muris in mice concurrently infected with Nematospiroides dubius. Annals of Tropical Medicine and Parasitology 78, 509-517.

Behnke, J.M., Pritchard, D.I., Wakelin, D., Park, J.R., McNicholas, A.M. \& Gilbert, F.S. (1994) Effect of ivermectin on infection with gastro-intestinal nematodes in Sierra Leone. Journal of Helminthology 68, 187-195.

Corbet, G.B. \& Harris, S. (1991) The handbook of British mammals. Oxford, Blackwell Scientific Press.

Crawley, M.T. (1993) GLIM for ecologists. Oxford, Blackwell Scientific Press.

Elliott, J.M. (1977) Some methods for the statistical analysis of samples of benthic invertebrates. Freshwater Biological Association, Cumbria, UK.

Elton, C., Ford, E.B., Baker, J.R. \& Gardiner, A.D. (1931) The health and parasites of a wild mouse population. Proceedings of the Zoological Society of London 1931, 657-721.

Gregory, R.D. (1992) On the interpretation of host-parasite ecology: Heligmosomoides polygyrus (Nematoda) in wild wood mouse (Apodemus sylvaticus) populations. Journal of Zoology 226, 109-121.

Gregory, R.D., Montgomery, S.S.J. \& Montgomery, W.I. (1992) Population biology of Heligmosomoides polygyrus (Nematoda) in the wood mouse. Journal of Animal Ecology 61, 749-757.

Haukisalmi, V. (1986) Frequency distributions of helminths in microtine rodents in Finnish Lapland. Annales Zoologici Fennici 23, 141-150.

Haukisalmi, V. \& Henttonen, H. (1993) Coexistence in helminths of the bank vole Clethrionomys glareolus. I. Patterns of co-occurrence. Journal of Animal Ecology 62, 221-229.

Haukisalmi, V., Henttonen, H. \& Tenora, F. (1988) Population dynamics of common and rare helminths in cyclic vole populations. Journal of Animal Ecology 57, 807-825.

Hominick, W.M. \& Aston, A.J. (1981) Association between Pelodera strongyloides (Nematoda: Rhabditidae) and wood mice, Apodemus sylvaticus. Parasitology 83, 67-75.

Keymer, A.E. \& Dobson, A.P. (1987) The ecology of helminths in populations of small mammals. Mammal Review 17, 105-116.

Khalil, L.F., Jones, A. \& Bray, R.A. (1994) Keys to the cestode parasites of vertebrates. Wallingford, CAB International.

Kisielewska, K. (1970) Ecological oraganization of intestinal helminth groupings in Clethrionomys glareolus (Schreb.) (Rodentia). 1. Structure and seasonal dynamics of helminth groupings in a host population in the Białowieża National Park. Acta Parasitologica Polonica 18, 121-147.

Kisielewska, K. (1971) Intestinal helminths as indicators of the age structure of Microtus arvalis Pallas, 1778 population. Bulletin de l'Academie Polonaise des Sciences. Serie des Sciences Biologiques Cl.II, 19, 275-282.

Kisielewska, K., Fraczak, K., Krasowska, I. \& Zubczewska, Z. (1973) Structure of the intestinal helminthocoenosis in the population of Microtus arvalis Pallas, 1778, and the mechanisms of its variability. Acta Parasitologica Polonica 21, 71-83.

Langley, R. \& Fairley, J.S. (1982) Seasonal variations in infestations of parasites in a wood mouse Apodemus sylvaticus population in the west of Ireland. Journal of Zoology 198, 249-261.

Lewis, J.W. (1968) Studies on the helminth parasites of the long-tailed field mouse, Apodemus sylvaticus sylvaticus from Wales. Journal of Zoology 154, 287-312.

Lewis, J.W. (1987) Helminth parasites of British rodents and insectivores. Mammal Review 17, 81-93.

Margolis L., Esch G.W., Holmes J.C., Kuris A.M. \& Schad G.A. (1982) The use of ecological terms in parasitology (Report of an ad hoc Committee of the American Society of Parasitologists). Journal of Parasitology 68, 131-133.

Montgomery, S.S.J. \& Montgomery, W.I. (1988) Cyclic and non-cyclic dynamics in populations of the helminth parasites of wood mice Apodemus sylvaticus. Journal of Helminthology 62, 78-90.

Montgomery, S.S.J. \& Montgomery, W.I. (1989) Spatial and temporal variation in the infracommunity structure of helminths of Apodemus sylvaticus (Rodentia: Muridae). Parasitology 98, 145-150.

Montgomery, S.S.J. \& Montgomery, W.I. (1990) Structure, stability and species interactions in helminth communities of wood mice Apodemus sylvaticus. International Journal for Parasitology 20, 225-242.

O'Sullivan, H.M., Small, C.M. \& Fairley, J.S. (1984) A study of parasitic infestations in populations of small rodents (Apodemus sylvaticus and Clethrionomys glareolus) on Ross Island, Killarney. Journal of Life Sciences, Royal Dublin Society 5, 29-42.

Prokopic, J. (1967) Hymenolepis muris-sylvatici (Rudolphi, $1819)=$ Variolepis crenata $($ Goeze, 1782). Folia Parasitologica 14, 365-369. 
Rudolphi, C.A. (1819) Entozoorum Synopsis. Berlin.

Sharpe, G.I. (1964) The helminth parasites of some small mammal communities. I. The parasites and their hosts. Parasitology 54, 145-154.

Tenora, F. (1967) Ecological study on helminths of small rodents of the Rohacska Dolina valley. Acta Scientiarum Naturalium Academiae Scientiarum Bohemoslovacae 1, 163-207.

Tenora, F. \& Stanek, M. (1995) Changes of the helmintho- fauna in several Muridae and Arvicolidae at Lednice in Moravia. II. Ecology. Acta Universitatis Agriculturae et Silviculturae Mendelianae Brunensis 43, 57-65.

Wilson, K. \& Grenfell, B.T. (1997) Generalized linear modelling for parasitologists. Parasitology Today 13, 33-38.

(Accepted 7 October 1998)

(C) CAB INTERNATIONAL, 1999 